\title{
UKRVO SPECTRAL PHOTOGRAPHIC ARCHIVE OF VARIABLE STARS
}

\author{
A.V. Zolotukhina, L.K. Pakuliak, I.B. Vavilova, B.M. Kaminsky \\ Main Astronomical Observatory of the NAS of Ukraine, \\ 27 Akademik Zabolotny St., Kyiv 03143 Ukraine \\ nastya@mao.kiev.ua
}

\begin{abstract}
The overview of the content of an Archive of the spectral photographic observational data stored at the MAO NAS of Ukraine in 1965-1985 is presented. Being the part of the UkrVO Joint Digitized Archive, this archive contains of 50,000 spectra of mostly variable stars.

The spectral photographic material (glass astroplates) was obtained by the 70-cm reflector AZT-2 (MAO NAS of Ukraine, Kyiv), 60-cm Zeiss telescope at the Mount Terskol (North Caucasus, Russia), and 1-m telescope at the Mount Sanglok (Institute of Astrophysics, Tajikistan) equipped with spectrographs UAGS with a set of gratings to obtain dispersions in the range of $29 \ldots 167 \mathrm{~A} / \mathrm{mm}$ of the wavelengths $3500 \ldots 6800 \mathrm{AA}$. There is also data related to the observations by the Double Short Astrograph (MAO NAS of Ukraine) with a pre-objective prism to monitor Nova Cygni 1975 in the initial stage of outburst. Almost all the spectra are calibrated with the 9-step attenuator and comparison spectra for the wavelength scale.

We discuss observational programs (aims, instruments, results), in frame of which this archive was accumulated, as well as key principles for digitizing spectra and their processing by modern tools of virtual observatory software.
\end{abstract}

Keywords: astroplates, database, variable stars, spectral photographic archive.

АНОТАЦІЯ. У роботі представлено огляд архіву даних спектральних спостережень, отриманих в ГАО НАН України з 1965 року. Цей архів охоплює період часу близько 20 років і містить 50000 спектрів, головним чином, змінних зір.

Спектральний фотоматеріал (скляні астропластинки) отриманий здебільшого на 70-см рефракторі АЗТ-2 (ГАО НАН України, Київ), а також 60-см телескопі Цейс високогірної обсерваторії на піку Терскол (Північний Кавказ, Росія) та 1-метровому телескопі на горі Санглок (Інститут астрофізики АН Таджикістану), оснащеному спектрографами UAGS 3 набором граток для отримання дисперсій $29 \ldots 167$ А/мм у діапазоні довжин хвиль 3500-6800 АА. А також дані, отримані на Подвійному широкутному астрографі (ГАО НАН України) з дооб’єктивною призмою для моніторингу Nova Cygni 1975 на початковій стадії спалаху. Майже всі спектри відкалібровані за допомогою 9ступінчастого аттенюатора та спектрів порівняння для шкали довжин хвиль.

У роботі розглянуто спостережні програми (мета, інструменти, результати), в рамках яких був накопичений цей архів, а також ключові принципи оцифрування спектрів та їх обробки сучасними інструментами програмного забезпечення віртуальної обсерваторії.

Ключові слова: астропластинки, бази даних, змінні зорі, спектральний фотографічний архів.

\section{Introduction}

In 2020, the next International Workshop on Stellar Spectral Libraries (IWSSL) was supposed to be held in Beijing. One of the main issues to be considered at the meeting can be defined as the problem of preparation of stellar spectral libraries (SSL) for data sharing, simplification of access to their archives, and the use of VO tools for the solution of the first two challenges (http://svo2. cab.inta-csic.es/projects/is$\mathrm{sibj} /$ ). The priority of this task is determined by the "considerable disagreements on the atmospheric parameters and chemical abundances of stars, and on the ages, metallicities of masses of galaxies, persist for decades" due to different approaches to observations, spectra restoration, and analysis used in every SSL, as it is noted in the objectives of IAU Commission G5 WG Stellar Spectral Libraries (https://www.iau.org/ science/scientific_bodies/working_groups/306/). Thus, the systematic uncertainties of SSLs prevent the resulted catalogues from providing the comprehensive coverage of the galactic evolution even if the internal accuracies of the components are extremely high.

David Montes presented the most complete list of SSLs of all types, both existing and future (https://webs.ucm.es/ info/Astrof/invest/actividad/spectra.html). We note some of the state-of-the-art SSLs.

X-Shooter Library (XSL) contains the collection of 3000 $25000 \AA$ medium-resolution $(\mathrm{R} \sim 10000)$ stellar spectra obtained with the X-Shooter spectrograph at the VLT in 20092010 (pilot program) and 2012-2014 (Large Program).

The second data release (Gonneau et al., 2020) contains 813 observations of 666 stars covered the extended wavelength range, including infrared data and spectral types between $\mathrm{O}$ and $\mathrm{M}$. Spectra are available via CDS http://cdsarc.u-strasbg.fr (ftp://130.79.128.5) or via http:// cdsarc.u-strasbg.fr/viz-bin/cat/J/A+A/634/ A133.

MILES Library contains near 1000 stars spanning a large range in atmospheric parameters. The spectra were obtained at the $2.5 \mathrm{~m}$ INT telescope and cover the range $3525-7500 \AA$ at $2.5 \AA$ (FWHM) spectral resolution.

The shape of the continuum for the stellar spectra has been carefully calibrated. The current version of the Library presents a high level of homogeneity (Falcón-Barroso et al., 
2011). The complete library is available as single tar files in ASCII and FITS formats at the website of the project as well as a set of WEBTOOLS to retrieve, handle and transform the data (http://miles.iac.es/pages/stellar-libraries. php). The VO access to the MILES was developed at Spanish VO (http://svo2.cab.inta-csic.esvocats/v2/miles/).

Gaia Benchmark stars (GBS) is a library of high resolution and high signal to noise ratio stellar spectra. Extremely high-resolution spectra of $\sim 40$ stars are spanning FGK spectral classes. The stars benefit from interferometric observations and have extremely accurate associated stellar parameters. This library can be used as a set of calibration stars for automatic stellar parameter pipeline developments in on-going spectroscopic surveys. Data are available through https://www.blancocuaresma.com/s/benchmarkstars or at the CDS as catalog III/281 (Blanco-Cuaresma et al., 2014).

Among the SSLs with low-resolution the LAMOST project (China's Large Sky Area Multi-Object Fiber Spectroscopic Telescope) stands out (Cui et al., 2012). The Empirical SSL from the LAMOST in its last release DR7 contains 14.5 million low (10.6 million) and medium resolution $(\mathrm{R} \sim 1800)$ flux calibrated spectra of $\sim 8$ million stars across the Galaxy with a wavelength coverage of the entire optical range. The number of high-quality $(\mathrm{S} / \mathrm{N}>10)$ spectra reaches 11.4 million. A catalogue, which has provided stellar parameters of 5.34 million stars, was also released in this data set. The DR7 is available at http:// dr7.lamost.org.

The examples of the design of SSL web-interfaces for data search and presentation of query results are the ELODIE online database of 35000 high-resolution stellar spectra (http://atlas.obs-hp.fr/elodie/) and the DAO Spectroscopic Plate Archive (http://www.cadc-ccda.hia-iha. nrc-cnrc.gc.ca/en/search/?collection=DAOPLATES\&noexec=true).

ELODIE archive preserves data obtained with ELODIE echelle spectrograph at $1.93 \mathrm{~m}$ telescope of Observatoire de Haute Provence. The spectra have the nominal resolution $\mathrm{R} \sim 42000$ and $\mathrm{S} / \mathrm{N}>3$. Spectra can be visualized on-screen or are available for download as FITS-files. The re-processing of data is organized on the fly as a pipeline. The present archive is extended with spectra of new instrument SOPHIE, which are available through the same interface.

The DAO spectroscopic plate collection consists of 1) over 16800 high-dispersion spectrograms exposed at the coudé focus of the 1.2-m DAO telescope and McKellar spectrograph between 1962 and 2000, and 2) more than 93 000 spectra obtained at the Cassegrain focus of the DAO 1.8-m telescope and spectrograph between 1918 and 1984. The interface of archive and query builder allow searches by important criteria (object name, date, wavelength) and presents the results of the search in a tabular format.

The NVO Virtual Observatory Spectrum Services (http://voservices.net/spectrum/default.aspx) proposes the web-interface for the search of objects in SDSS DR6 collection by means of related $\mathrm{VO}$ services built using the $\mathrm{VO}$ ConeSearch standard. The collection of spectra is expandable. The registered users can upload their own spectra and use VO tools for their processing. The site provides several visualization and computational tools (Dobos et al., 2004).
The list of available VO tools and software for processing the spectral data can be accessed through the IVOA web-site https://www.ivoa.net/astronomers/applications. html.

So, a vast amount of spectral data with a quality from low to medium resolution is available from releases of the Gaia space mission and its complementary ground-based spectroscopic surveys.

The question is: why, having millionth SSL, we intend to digitize spectral photographic archives with dozens or hundreds of objects? Which science could be done with archival data?

The answer is: a collation of archival and modern observational data is crucial for astronomical objects, which manifest variability of their physical parameters (novae, variable stars, multiple systems) and might display new facts (for example, as $\in$ Aurigae) about properties during evolution (Griffin, 2013).

The correct digitization and treatment of the old stellar spectra, regardless of apparent quality, is the main demand for the glass collections of spectral plates to preserve the information which they bear.

\section{The UkrVO database of spectral archive}

The glass library of the MAO NAS of Ukraine is still a hard-to-reach repository of a huge amount of astronomical data. Searching for information even in a separate glass archive is an almost impossible task due to problems of its orderliness, visibility, the ability to use search algorithms, time consumption, performance, media aging, physical loss of information, etc. Digitized archives are devoid of all these shortcomings and make it possible to obtain information in full on a set of archives and at finite intervals (Vavilova et al., 2011, 2020; Savanevych et al. 2015, 2017).

At the moment, the Ukrainian VO archive contains of 654 digitized spectral astronegatives, mostly of variable stars. Table 1 shows the name and type of stars as well as the number of spectral astronegatives for these objects.

We started the process of digitizing this collection with the photographic spectra, which can be systematized. It aims at creation a database of free access using modern image digitizing technologies. Plate digitizing is conducted using a flatbed scanner Epson Expression 10000XL with 16-bit gray levels, resolution of 4800 dpi. Digitized images are stored in TIFF and FITS formats (http://ukr-vo. org/spectra/). The SSL database is described by Pakuliak et al. (2014).

\section{Observational and research projects}

The spectral photographic material (glass astroplates) was obtained by the 70-cm reflector AZT-2 (MAO NAS of Ukraine, Kyiv), 60-cm Zeiss telescope at the Mount Terskol (North Caucasus, Russia), and 1-m telescope at the Mount Sanglok (Institute of Astrophysics, Tajikistan) equipped with spectrographs UAGS with a set of gratings to obtain dispersions in the range of $29 \ldots 167 \mathrm{~A} / \mathrm{mm}$ in the wavelengths $3500 \ldots 6800 \mathrm{AA}$. 
Table 1. Description of the UkrVO archive of spectral photographic astroplates with variable stars observed in 19651985 and stored at the MAO NAS of Ukraine

\begin{tabular}{|c|c|c|c|}
\hline No. & Object & $\begin{array}{c}\text { Number } \\
\text { of spec- } \\
\text { tral as- } \\
\text { tronega- } \\
\text { tives }\end{array}$ & $\begin{array}{c}\text { Type } \\
\text { (SIMBAD) }\end{array}$ \\
\hline 1 & R And & 26 & S Star \\
\hline 2 & W And & 14 & S Star \\
\hline 3 & EG And & 5 & Symbiotic Star \\
\hline 4 & $\beta$ And & 14 & $\begin{array}{l}\text { High proper- } \\
\text { motion Star }\end{array}$ \\
\hline 5 & $\alpha \mathrm{Aql}$ & 5 & $\begin{array}{l}\text { Variable Star of } \\
\text { delta Sct type }\end{array}$ \\
\hline 6 & y Aql & 11 & Star \\
\hline 7 & $\alpha \mathrm{Aqr}$ & 7 & Star \\
\hline 8 & R Boo & 1 & $\begin{array}{l}\text { Variable Star of } \\
\text { Mira Cet type }\end{array}$ \\
\hline 9 & V Boo & 1 & $\begin{array}{l}\text { Long-period } \\
\text { variable star }\end{array}$ \\
\hline 10 & $\eta$ Boo & 6 & $\begin{array}{l}\text { Spectroscopic } \\
\text { binary }\end{array}$ \\
\hline 11 & R Cam & 2 & S Star \\
\hline 12 & T Cam & 6 & S Star \\
\hline 13 & XX Cam & 1 & $\begin{array}{c}\text { Variable Star of } \\
\text { R CrB type }\end{array}$ \\
\hline 14 & R Cas & 22 & $\begin{array}{l}\text { Variable Star of } \\
\text { Mira Cet type }\end{array}$ \\
\hline 15 & T Cas & 4 & $\begin{array}{l}\text { Variable Star of } \\
\text { Mira Cet type }\end{array}$ \\
\hline 16 & V Cas & 6 & $\begin{array}{l}\text { Variable Star of } \\
\text { Mira Cet type }\end{array}$ \\
\hline 17 & SU Cas & 1 & $\begin{array}{l}\text { Classical Cepheid } \\
\text { (delta Cep type) }\end{array}$ \\
\hline 18 & TU Cas & 1 & $\begin{array}{l}\text { Classical Cepheid } \\
\text { (delta Cep type) }\end{array}$ \\
\hline 19 & UV Cas & 2 & $\begin{array}{c}\text { Variable Star of R } \\
\text { CrB type }\end{array}$ \\
\hline 20 & $\beta$ Cas & 12 & $\begin{array}{l}\text { Variable Star of } \\
\text { delta Sct type }\end{array}$ \\
\hline 21 & $\delta$ Cas & 2 & $\begin{array}{l}\text { Eclipsing binary } \\
\text { of Algol type }\end{array}$ \\
\hline 22 & $\eta$ Cep & 15 & $\begin{array}{l}\text { High proper- } \\
\text { motion Star }\end{array}$ \\
\hline 23 & o Cet & 2 & $\begin{array}{l}\text { Variable Star of } \\
\text { Mira Cet type }\end{array}$ \\
\hline 24 & $\tau$ Cet & 6 & $\begin{array}{l}\text { High proper- } \\
\text { motion Star }\end{array}$ \\
\hline 25 & V Cnc & 2 & S Star \\
\hline 26 & $\mathrm{~S} \mathrm{CrB}$ & 3 & $\begin{array}{l}\text { Variable Star of } \\
\text { Mira Cet type }\end{array}$ \\
\hline 27 & R Cyg & 2 & S Star \\
\hline 28 & U Cyg & 2 & Carbon Star \\
\hline 29 & $\mathrm{CH}$ Cyg & 210 & Symbiotic Star \\
\hline 30 & RT Cyg & 6 & $\begin{array}{l}\text { Variable Star of } \\
\text { Mira Cet type }\end{array}$ \\
\hline 31 & RU Cyg & 2 & $\begin{array}{l}\text { Variable Star of } \\
\text { Mira Cet type }\end{array}$ \\
\hline 32 & ₹ Cyg & 2 & Variable Star \\
\hline
\end{tabular}

\begin{tabular}{|c|c|c|c|}
\hline 33 & $\delta$ Cyg & 1 & $\begin{array}{l}\text { High proper- } \\
\text { motion Star }\end{array}$ \\
\hline 34 & $\zeta$ Cyg & 7 & $\begin{array}{l}\text { Spectroscopic } \\
\text { binary }\end{array}$ \\
\hline 35 & $\xi$ Cyg & 17 & $\begin{array}{c}\text { Spectroscopic } \\
\text { binary }\end{array}$ \\
\hline 36 & UX Dra & 2 & Carbon Star \\
\hline 37 & $\beta$ Dra & 20 & Star \\
\hline 38 & $\chi$ Dra & 5 & $\begin{array}{l}\text { Spectroscopic } \\
\text { binary }\end{array}$ \\
\hline 39 & $\varepsilon$ Eri & 3 & $\begin{array}{c}\text { Variable of BY } \\
\text { Dra type }\end{array}$ \\
\hline 40 & R CMi & 4 & S Star \\
\hline 41 & $\beta$ Gem & 24 & $\begin{array}{l}\text { High proper- } \\
\text { motion Star }\end{array}$ \\
\hline 42 & $\gamma \mathrm{Gem}$ & 1 & $\begin{array}{c}\text { Spectroscopic } \\
\text { binary }\end{array}$ \\
\hline 43 & $\varepsilon$ Gem & 7 & Variable Star \\
\hline 44 & $\mu \mathrm{Gem}$ & 7 & $\begin{array}{l}\text { Long-period } \\
\text { variable star }\end{array}$ \\
\hline 45 & $\xi \mathrm{Gem}$ & 6 & $\begin{array}{l}\text { High proper- } \\
\text { motion Star }\end{array}$ \\
\hline 46 & $\rho$ Gem & 1 & $\begin{array}{l}\text { High proper- } \\
\text { motion Star }\end{array}$ \\
\hline 47 & v Gem & 1 & $\begin{array}{l}\text { High proper- } \\
\text { motion Star }\end{array}$ \\
\hline 48 & $\alpha$ Her & 18 & $\begin{array}{c}\text { Double or } \\
\text { multiple star }\end{array}$ \\
\hline 49 & $\mu \mathrm{Her}$ & 17 & $\begin{array}{c}\text { Double or } \\
\text { multiple star }\end{array}$ \\
\hline 50 & $\varepsilon$ Нyа & 5 & $\begin{array}{l}\text { Rotationally } \\
\text { variable Star }\end{array}$ \\
\hline 51 & Sp K & 3 & $\begin{array}{c}\text { Unknown star, } \\
\text { possibly K-type } \\
\text { star } \\
\text { for comparison }\end{array}$ \\
\hline 52 & R Leo & 6 & $\begin{array}{c}\text { Variable Star of } \\
\text { Mira Cet type }\end{array}$ \\
\hline 53 & $\zeta$ Leo & 7 & Variable Star \\
\hline 54 & $\eta$ Leo & 3 & Star \\
\hline 55 & $\alpha$ Lep & 3 & Variable Star \\
\hline 56 & R Lyr & 3 & $\begin{array}{l}\text { Long-period } \\
\text { variable star }\end{array}$ \\
\hline 57 & W Lyr & 4 & $\begin{array}{c}\text { Variable Star of } \\
\text { Mira Cet type }\end{array}$ \\
\hline 58 & $\alpha \mathrm{Oph}$ & 7 & $\begin{array}{c}\text { Double or } \\
\text { multiple star }\end{array}$ \\
\hline 59 & $\alpha$ Ori & 10 & $\begin{array}{c}\text { Red supergiant } \\
\text { star }\end{array}$ \\
\hline 60 & $\beta$ Ori & 9 & $\begin{array}{c}\text { Blue supergiant } \\
\text { star }\end{array}$ \\
\hline 61 & $\pi^{3}$ Ori & 2 & $\begin{array}{l}\text { High proper- } \\
\text { motion Star }\end{array}$ \\
\hline 62 & v Peg & 4 & $\begin{array}{l}\text { High proper- } \\
\text { motion Star }\end{array}$ \\
\hline 63 & $\alpha$ Per & 13 & Variable Star \\
\hline 64 & y Per & 1 & $\begin{array}{c}\text { Eclipsing binary } \\
\text { of Algol type }\end{array}$ \\
\hline 65 & $v$ Per & 3 & Star \\
\hline 66 & V Sge & 1 & Nova-like Star \\
\hline
\end{tabular}




\begin{tabular}{|c|c|c|c|}
\hline 67 & SU Tau & 1 & $\begin{array}{c}\text { Variable Star of R } \\
\text { CrB type }\end{array}$ \\
\hline 68 & $\alpha$ Tau & 15 & $\begin{array}{c}\text { Long Period } \\
\text { Variable } \\
\text { candidate }\end{array}$ \\
\hline 69 & R Tri & 4 & $\begin{array}{c}\text { Variable Star of } \\
\text { Mira Cet type }\end{array}$ \\
\hline 70 & R UMa & 2 & $\begin{array}{c}\text { Variable Star of } \\
\text { Mira Cet type }\end{array}$ \\
\hline 71 & $\beta$ UMa & 1 & $\begin{array}{c}\text { High proper- } \\
\text { motion Star }\end{array}$ \\
\hline 72 & R Vir & 3 & $\begin{array}{c}\text { Variable Star of } \\
\text { Mira Cet type }\end{array}$ \\
\hline 73 & r Vir & 1 & $\begin{array}{c}\text { Double or } \\
\text { multiple star }\end{array}$ \\
\hline 74 & R CVn & 1 & $\begin{array}{c}\text { Variable star of } \\
\text { Mira Cet type }\end{array}$ \\
\hline
\end{tabular}

The first instrument AZT-2 $(\mathrm{D}=70 \mathrm{~cm})$ was mounted in 1959 at the MAO NASU (Fig. 1) for astrophysical purposes: photometric, spectral, and polarimetric observations of the Solar System bodies and stars.

The research on stellar spectroscopy have started at the MAO NASU in 1960. They were initiated by Prof. Tsesevich V.P. and conducted later by his post-graduate students and followers (Andronov, 2017; Vavilova, 2017). Among them were I.G. Zhdanova, F.I. Lukatskaya, R.I. Chupryna, and later (the "Odessa landing") M.Ya. Orlov (research of $\mathrm{RCrB}$ type stars with anomalous chemical composition), M.G. Rodriges (research of stars of late spectral classes), A.F. Pugach (research of physics of non-stationary stars), E.S. Kheilo (variable stars in globular clusters, astronomical instrumentation) and yet later, G.U. Kovalchuk, A.E. Rozenbush, R.M. Goncharova.

Observations were carried out at the AZT-2 in Golosiivo (MAO NASU), at large telescopes of the Crimean Astrophysical Observatory (CrAO) and Shemakha Astrophysical Observatory (ShAO). Spectral-photometric archive of the MAO NASU is stored within a large number of observational projects related to the variable stars of different types. The observational data are not fully digitized and systematized due to the absence of observation's protocols in several cases. We note several programs.

In 1972, under the leadership of M.Ya. Orlov, the complex studies of non-stationary stars of the R Northern Corona type $(\mathrm{R} \mathrm{CrB})$ began, which are characterized by anomalous physical composition (significant hydrogen deficiency, carbon excess) and the presence of non-stationary dust shells, sometimes so dense, that the apparent brightness of the star is weakened by several magnitudes.

In 1974, the photoelectric observations of nonstationary stars were conducted by Pugach A.F., Kovalchuk G.U., and Kondratyuk R.R. with AZT-14 at the Terskol Observatory and with MTM-500 television set at the Crimean AO. Then exactly, the spectral and polarimetric observations of UV Cas, a little-studied star of the R CrB type, have begun. Spectral observations of stars of the late spectral types were continued with AZT-2, the Zeiss universal diffraction spectrograph. As a result, 102 spectrograms were obtained (Annual Scientific Report of the MAO NASU, 1974, p. 58);

Catalog of B-V stellar magnitudes of spectra of about 20000 stars has been prepared for printing and the spectra of early stars up to $15^{\mathrm{m}}$ in the region of the NGC2129 cluster have been recorded (i.e., p. 60); 900 double scans were obtained at the Terskol Observatory (i.e., p. 80).

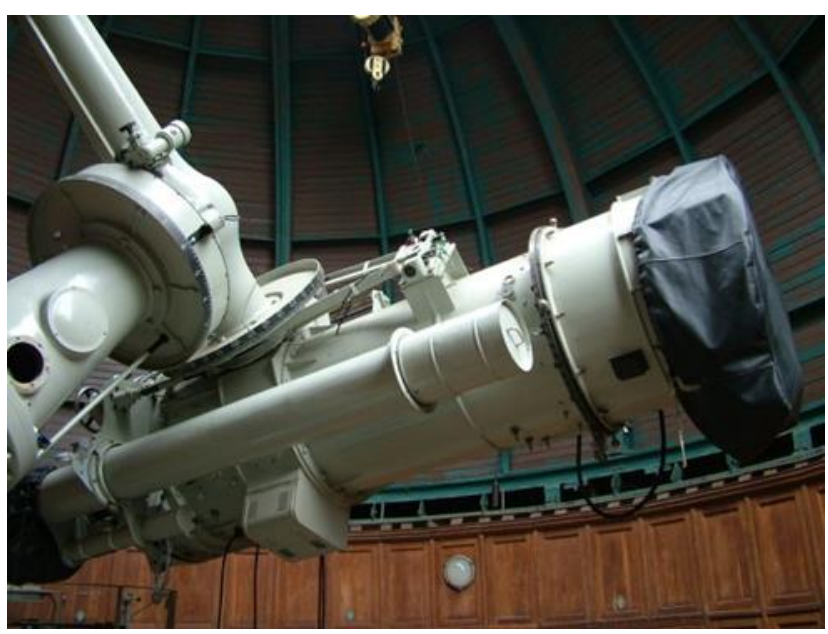

Figure 1: The $70 \mathrm{~cm}$ reflector AZT-2 (MAO NAS of Ukraine, Kyiv)

In 1978, the four-color observations of non-stationary stars with non-periodic brightness attenuation were carried out (RZ Psc, V530 Cyg, BO Cep, XY Per, RCrB) (Annual Scientific Report of the MAO NASU, 1978, p. 60); the energy distribution in the spectrum of $\eta \mathrm{Agl}$ was obtained for the first time by E.A. Depenchuk (i.e., p. 105).

In 1978, under the "Nadir" research program, the images of variable stars were registered with the scanning spectrometer at the observational station "Lisnyky" (Kyiv National University). The AZT-2 telescope in Golosiivo allowed obtaining 35 scans with a dispersion of $84 \AA / \mathrm{mm}$ of Cepheids and standard stars of spectral types F-G. A cata$\log$ of equivalent absorption line widths in the RR Lyra spectra has been prepared for publication (i.e., p. 106).

In 1985, the debugging and testing of the operability of the interface of the automatic electro-spectrophotometer with the control micro-computer "Electronica DZ-28" (E.A. Depenchuk, A.F. Pereverzentsev) was completed. Trial observations were carried out at the Mayaki astronomical station near Odessa. Then the equipment was delivered to the Terskol Observatory and installed at the AT-80 telescope (Annual Report of the MAO NASU, 1985, p. 105).

The bigger collection of observations of variable stars, which are at the disposal of the Astronomical Observatory of the I.I. Mechnikov National University of Odesa, numbers $\sim 84000$ photographic plates obtained with the 7-camera astrograph at the Mayaky station in 1957-1998 (Chochol et al. 1999; Šimon et al. 2002; Andronov et al. 2014). It could be used as the complemented photometric data while studying spectra of individual variable stars. Some description about collection of spectral and photometric observations of stars stored at the CrAO (Shlyapnikov et al. 2019) can be found through web-site of the Crimean Virtual Observatory (https://sites. google.com/view/cravo-invo/about). 


\section{Digital versions of star spectra from photographic astronegatives}

Figure 2 shows a digital version of the XX Cam spectrogram from the MAO archive as the example. It includes information about the star's name (XX Cam), date of observation (Oct 15/16, 1978), number in the journal of observations (Z-413) as well as the time of exposure (70 $\mathrm{min})$.

This object (No. 13 in Table 1) has only one spectrogram that make unable to use it for the following study with a spectral archive of the MAO NASU. Object of observation: the star XX Cam $\left[\alpha(J 2000)=04^{\mathrm{h}} 08^{\mathrm{m}} 38.7^{\mathrm{s}}, \delta(\mathrm{J} 2000)=+53^{\circ} 21^{\prime} 39.35^{\prime \prime}\right]$, one of the brightest stars of the $\mathrm{R} \mathrm{CrB}$ type $\left(\mathrm{V}=7^{\mathrm{m}} .35\right)$, radial velocity $15.5 \mathrm{~km} / \mathrm{s}$, parallaxes $0.6407 \pm 0.0355$ mas, spectral type F8I C, Gaia DR2 275138564223556608. From the year 1898 till to date, apparently XX Cam has undergone only one visual brightness light minimum in 1939-1940. From inspection of a single low-dispersion spectrogram obtained in 1947, Bidelman (1948) noted abnormal weakness of the hydrogen lines and presence of the lines carbon as well as he marked general similarity of the spectra of XX Cam and R CrB (Orlov \& Rodriguez, 1974). The stars of $\mathrm{R} C r B$ type were deeply studied in various observational programs of the MAO NASU, see, for example, the monograph by Zhiliaev et al. (1978) and papers by Začs et al. (2007), Yakovina et al. (2013). The R CrB stars as the longterm variables are of particular interest for the modern projects such as the VASCO (Villarroel et al. 2020).

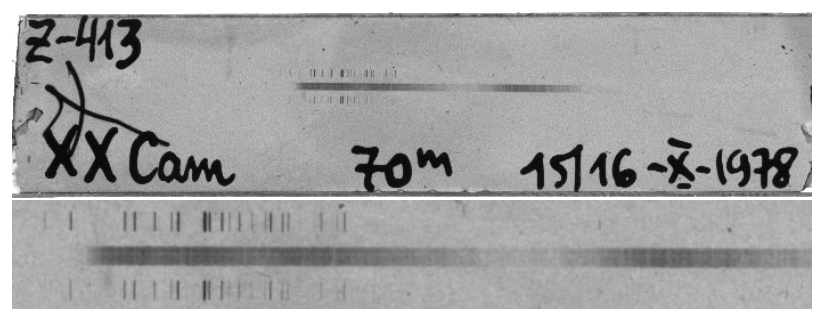

Figure 2: Digital version of the XX Cam spectrogram from the spectral archive of the MAO NASU

One of the interesting objects from a spectral archive is the R And (No. 1 in Table 1, 24 spectral astronegatives, Gaia DR2 379224622732758528). Object of observation (Fig. 3): R And $\left[\alpha(\mathrm{J} 2000)=00^{\mathrm{h}} 24^{\mathrm{m}} 01.95^{\mathrm{s}}, \delta(\mathrm{J} 2000)=\right.$ $\left.+38^{\circ} 34^{\prime} 37.33^{\prime \prime}\right], S$ star $\left(\mathrm{V}=5.8^{\mathrm{m}}-15.2^{\mathrm{m}}\right)$, parallaxes $4.1281 \pm 0.4616$ mas, radial velocity $-6.40 \mathrm{~km} / \mathrm{s}$, spectral type $55-7 / 4-5$ e B. It shows periodic variations in brightness approximately every 409 days (Samus et al., 2009).

The spectrum visualization of digitized spectrogram of $\mathrm{R}$ And in scale of scan is given in Fig. 4. It obtained with software developed by S.G. Sergeev (Crimean Astrophysical Observatory), which creates a standard FITS file with the required header parameters. That is, the source file will be interpreted by any spectra processing software tools likely IVOA VOSpec (Baines et al., 2009), Aladin, DECH20 (Galazutdinov, 1992) etc. As a result, it will be possible to "breathe new life" in old spectral photographic archives of variable stars from their discovery (for example, Pickering, 1895) to nowadays research: chemical composition and molecular spectra (Lambert 1988), spectral variability (Začs et al., 2016), methods of processing (Calderon et al., 2002), VO spectral stellar library (Mickaelian et al., 2017) etc.

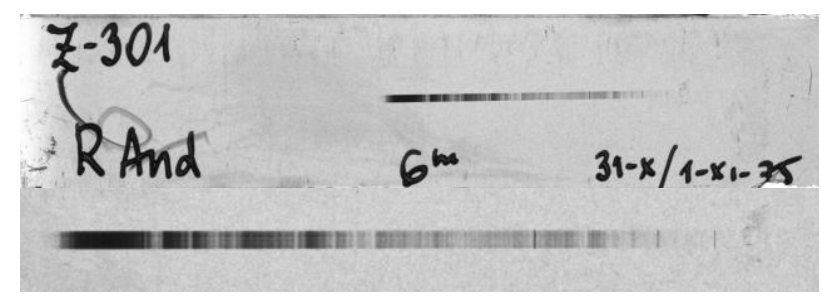

Figure 3: Digital version of the R And spectrogram from the photographic archive of the MAO NASU (observation date: Oct 31 - Nov 1, 1975; exposure: 6 min)

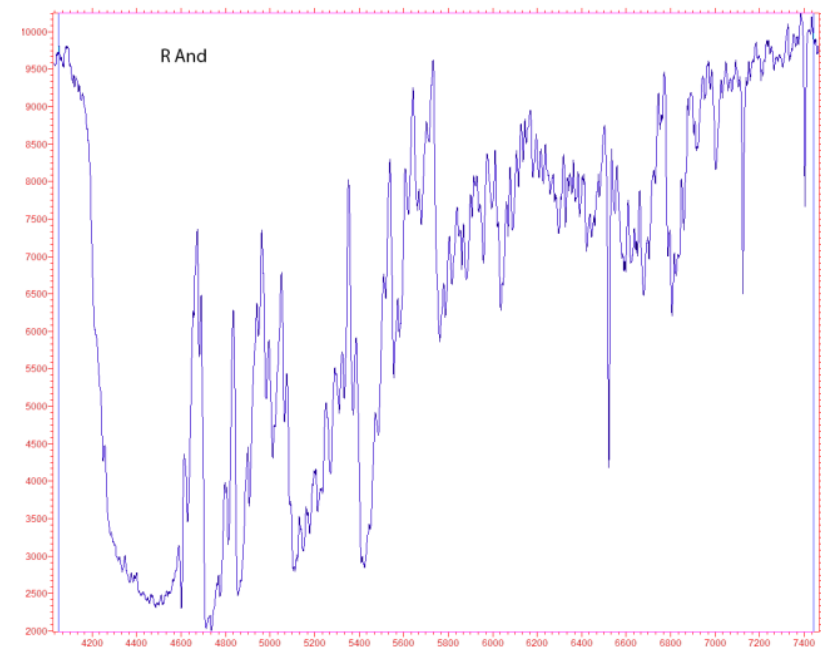

Figure 4: Visualization of R And spectrum from the digitized astronegatives in scale of scan as in Figure 3 (axis $\mathrm{X}$ : in pixels of $\mathrm{X}$ axis of scan; axis $\mathrm{Y}$ : relative flux)

\section{Conclusion}

We describe the start points of the new UkrVO project related to the development of database of astronegatives with stellar spectra from the archive of the MAO NASU. Now it contains 654 systematized spectra, mostly of variable stars, and covers observational period of 1965-1985 years. We envisage the main stages of the project as follows:

- Systematization of spectra collection (creation of database for the archive of photographic stellar spectrograms).

- Search for any reports on the topic and for annual reports in the archieve of the MAO NASU with description of the observational material (instruments, objectives of observational programs, observers, results etc.).

- Search for scientific articles written by observers that describe their results and observational programs, etc.

- Digitization of star's spectra.

- Further reduction of spectra extracted from astronomical negatives, including programs to compute astrometric solution, extract spectra, and apply wavelength and photometric calibration for objects.

- Interactive access and processing of digital versions of spectra.

- Identification of spectral lines. 
- Scientific project with archive of Spectral Digital Library of the UkrVO (http://ukr-vo.org/spectra/).

The implementation of advanced digital technologies to ensure the interactive use of accumulated data on archive spectra of individual stars is of particular relevance, given the possibility of retrospective analysis of their state at time intervals from decades to days.

Acknowledgements. This research has made use of the SIMBAD database, operated at CDS, Strasbourg, France (Wenger et al. 2000).

\section{References}

Andronov I.L.: 2017, Odessa Astron. Publ., 30, 252. DOI: 10.18524/1810-4215.2017.30.118686

Andronov I.L., Marsakova V.I., Kudashkina L.S.: 2014 Adv. Astron. Space Phys., 4, 3.

Annual Scientific Report of the MAO NAS of Ukraine: 1974, Kyiv, 88 p.

Annual Scientific Report of the MAO NAS of Ukraine: 1978, Kyiv, 111 p.

Annual Scientific Report of the MAO NAS of Ukraine: 1985, Kyiv, 126 p.

Baines D., P. Osuna, Gonzalez-Núñez J.: 2009, Multi-wavelength Astronomy using VOSpec. Proceedings of the EURO-VO Workshop, held at the ESA, 2008. ESA, p. 99.

Bidelman W. P.: 1948, Astrophys. J., 107, 413.

Blanco-Cuaresma S., Soubiran C., Jofré P., Heiter U.: 2014 $A \& A, \mathbf{5 6 6}, 98$. DOI:10.1051/0004-6361/201323153

Calderón J.H., Villada M., Bustos F.: 2002, Revista Mexicana de Astronomia y Astrofisica Serie de Conferencias, 14, 148.

Chochol D., Andronov I.L., Arkhipova V.P.: 1999, Contrib. Astron. Obs. Skalnate Pleso, 29, 1, 31

Cui X.-Q., Zhao Y.-H., Chu Y.-Q. et al.: 2012, Research in Astronomy and Astrophysics, 12, Is. 9, 1197. DOI:10.1088/1674-4527/12/9/003

Dobos L., Budavári T., Csabai I., Szalay A.S.: 2004, Astronomical Data Analysis Software and Systems (ADASS) XIII, 314, 185.

Falcón-Barroso J., Sánchez-Blázquez P., Vazdekis A. et al.: 2011, Astron. \& Astrophys., 532, 95. DOI: 10.1051/0004-6361/201116842

Galazutdinov G.A.: 1992, Eshele-spectra processing system DECH-20, Preprint No. 92 (Spec. Astrophys. Observ., Nizhny Arkhyz), 52.

Gonneau A., Lyubenova M., Lançon A. et al.: 2020, Astron. \& Astrophys., 634, 133. DOI: 10.1051/00046361/201936825

Griffin R.E., Stencel R.E.: 2013, PASP, 125, Is. 929, 775. DOI: $10.1086 / 671781$
Kashuba S.G., Bazyey N.V., Kashuba V.I., Andrievsky S.M.: 2019, In: Large surveys with small telescopes: Past, Present, and Future (AstroplateIII); https://www.plate-archive.org/applause/wp-content/uploads/2019/04/Bazyey_Odessa_Archive.pdf

Lambert D.L.: 1988, Publ. Astron. Soc. Pac., 100, 1202.

Mickaelian A.M., Astsatryan H.V., Knyazyan A.V., Mikayelyan G.A.: 2017, BAOJ Physics, 2, Is. 1, id. 8, 11.

Orlov M.Ya.: 1975, Perem. Zvezdy, Byull., 19, 6, 501.

Orlov M.Ya., Rodriguez M. H.: 1974, Astron. \& Astrophys., 31, 203.

Pakuliak L., Shlyapnikov A., Rosenbush A. et al.: 2014, International Workshop on Stellar Spectral Libraries ASI Conference Series, 11, 103 (digital versions).

Pickering E.C.: 1895, Astrophys. J., 1, 27.

Samus N.N., Kazarovets E.V., Durlevich O.V. et al.: 2009, VizieR Online Data Catalog: General Catalogue of Variable Stars (Samus+ 2007-2017): B/gcvs. Originally Published In: 2017ARep...61...80S.

Savanevych V.E., Briukhovetskyi A.B., Sokovikova N.S. et al.: 2015, Mon. Not. R. Astron. Soc., 451, 3, 3287. DOI: $10.1093 / \mathrm{mnras} / \mathrm{stv} 1124$

Savanevych V.E., Khlamov S.V., Vavilova I.B. et al.: 2018, Astron. \& Astrophys., 609, id. A54, 11 pp. DOI: 10.1051/0004-6361/201630323

Shlyapnikov A.A., Gorbunov M.A., Gorbachev R.R. et al.: 2019, Izv. Krymsk. Astrofiz. Observ., 115, 1, 38 (In Russian).

Šimon V., Hric L., Petrík K.: 2002, Astron. Astrophys., 393, 921

Vavilova I.B.: 2016, Odessa Astron. Publ., 29, 109. DOI: 10.18524/1810-4215.2016.29.85269

Vavilova I.B.: 2017, Odessa Astron. Publ., 30, 256. DOI: 10.18524/1810-4215.2017.30.118718

Vavilova I.B., Pakuliak L.K., Protsyuk Yu.I. et al.: 2011, Kosm. nauka tehnol., 17, 4, 74.

Vavilova I., Pakuliak L., Babyk Iu. et al.: 2020, "Surveys, Catalogues, Databases, and Archives of Astronomical Data" in "Knowledge Discovery in Big Data from Astronomy and Earth Observation", p. 57-102. DOI: 10.1016/ B978-0-12-819154-5.00015-1

Villarroel B., Soodla J., Comeron S. et al.: 2020, Astron. J., 159, 1, 8. DOI: $10.3847 / 1538-3881 /$ ab570f

Wenger et al.: 2000, The SIMBAD astronomical database, Astron. \& Astrophys. Suppl., 143, 9.

Yakovina L.A., Rosenbush A.E., Pavlenko Ya.V., Kaminsky B.M.: 2013, Astronomy Reports, 57, Is. 10, 734.

Začs L., Mondal S., Chen W.P. et al.: 2007, Astron. \& Astrophys., 472, Is. 1, 247.

Začs L., Musaev F., Kaminsky B. et al.: 2016, Astrophys. J., 816, Is. 1, article id. 3, 14 pp.

Zhiliaev B.E., Orlov M.Ia., Pugach A.F. et al.: 1978, R Coronae Borealis type stars. Kiev: Nauk. Dumka, 128 p. (in Russian). 